\title{
O lenço de pano e o buquê de flores: Estados nacionais e os povos tukano orientais na fronteira colombo-brasileira
}

The handkerchief and the flower bouquet: National states and Western

Tukanoans at the Colombia-Brazil border

\section{Luis Cayón}

\section{Q OpenEdition Journals}

\section{Edição electrónica}

URL: http://journals.openedition.org/aa/3182

DOI: $10.4000 /$ aa. 3182

ISSN: 2357-738X

\section{Editora}

Programa de Pós-Graduação em Antropologia Social (UnB)

\section{Edição impressa}

Data de publição: 1 dezembro 2018

Paginação: 83-111

ISSN: 0102-4302

\section{Refêrencia eletrónica}

Luis Cayón, «O lenço de pano e o buquê de flores: Estados nacionais e os povos tukano orientais na fronteira colombo-brasileira», Anuário Antropológico [Online], v.43 n.2 | 2018, posto online no dia 26 maio 2019, consultado o 28 abril 2021. URL: http://journals.openedition.org/aa/3182 ; DOl: https:// doi.org/10.4000/aa.3182

\section{@) $\Theta \Theta \Theta$}

Anuário Antropológico is licensed under a Creative Commons Atribuição-Uso Não-Comercial-Proibição de realização de Obras Derivadas 4.0 International. 


\section{O lenço de pano e o buquê de flores}

\section{Estados nacionais e os povos tukano orientais na fronteira colombo-brasileira}

Luis Cayón

UnB

\section{Introdução}

Numa sufocante tarde de calor num domingo de agosto de 1995, cheguei a La Pedrera, uma pequena vila à beira do rio Caquetá (Japurá, como é conhecido no Brasil), para iniciar meu trabalho de campo entre os Makuna, um povo tukano oriental da Amazônia colombiana. Na época, eu era um jovem aspirante a etnógrafo que, pela primeira vez na vida, tinha que se virar sozinho em terras desconhecidas. La Pedrera era - e ainda é - o último enclave do Estado colombiano nesse rio, e a tímida presença estatal na região limitava-se apenas a um pelotão do exército, uns poucos policiais e um pequeno hospital. La Pedrera tinha vivido seu auge poucos anos antes, no final da década de 1980, quando contingentes de comerciantes, prostitutas e garimpeiros colombianos e brasileiros compravam lá os produtos para sustentar-se durante as temporadas de trabalho na extração ilegal de ouro, na serra do rio Traíra, cujo curso marca a fronteira por uns 160 quilômetros. Depois da decadência do garimpo, os comerciantes de La Pedrera construíram câmaras frias para armazenar grandes quantidades de peixe que, quando lá cheguei, escoavam para as grandes cidades do interior. A vila estava praticamente desconectada do resto do país e mais ligada ao Brasil. Comunicava-se com Leticia (capital do departamento do Amazonas) apenas por um voo semanal e com Bogotá pelo voo mensal de apoio do Exército. Se eu viajasse a montante, poderia passar vários dias atravessando diversos territórios indígenas até encontrar outro povoado colombiano, enquanto a jusante, em umas duas horas chegaria a Vila Bittencourt, no Brasil.

Durante a semana que passei no povoado tentando articular minha viagem para o território makuna, algumas coisas chamaram minha atenção sobre as condições em que viviam os índios: embora os habitantes da vila fossem majoritariamente indígenas, o poder estava nas mãos de um punhado de comerciantes que pagavam miseravelmente pelos diversos serviços que os índios lhes prestavam; os preços das mercadorias, salvo a cachaça brasileira, eram exorbitantes porque tudo era trans- 
portado por via fluvial e demorava semanas a chegar; os indígenas estavam acostumados com as relações de exploração dos seus "patrões" comerciantes e era muito comum ouvi-los contar histórias sobre distintos patrões que tiveram na Colômbia e no Brasil, orgulhando-se dos seus conhecimentos de português e espanhol assim como dos lugares que visitaram. Na época, pensei que eles estavam esmagados entre os projetos civilizatórios do Brasil e da Colômbia e não percebi que havia um complexo sistema de relações sociais nessa região de fronteira que permitia aos índios lidar de maneiras diferentes com os dois Estados.

Em retrospectiva, vejo que durante aqueles primeiros dias em La Pedrera vivenciei uma tríplice fronteira: entre a Colômbia e o Brasil, entre a sociedade nacional e os índios, e entre a própria sociedade colombiana e sua fronteira de colonização. Na breve experiência em La Pedrera, senti-me aturdido pela quantidade de línguas diferentes que ouvia e não entendia, incluindo o português, e pelo estupor produzido por um estranhamento para o qual nunca me prepararam as reflexões metodológicas dos mestres da antropologia. Estava numa "situação fronteiriça" que, no mínimo, era geográfica, cultural, política, social, econômica e moral que, pela primeira vez, e simultaneamente, me fazia sentir as várias escalas da minha identidade como colombiano, branco, cidadão, jovem urbano, estudante universitário, etc., atingindo de uma forma nova e desconhecida minhas emoções e pensamentos; por isso, salvo os primeiros momentos da paternidade, outra situação fronteiriça, é difícil lembrar-me de um sentimento tão apavorante, confuso e de insignificância como esse primeiro encontro com alteridades diversas. Dias depois, quando cheguei na primeira aldeia makuna, saí daquele estado de estupor, senti-me acolhido e, paradoxalmente, menos inseguro. Embora não entendesse a língua, era muito mais fácil sentir-me ignorante, pois tinha apenas um universo novo para descobrir e estava mentalmente preparado para isso. Esse era o tipo de estranhamento que, depois de imaginar Malinowski sozinho com sua bagagem numa praia das ilhas Trobriand, olhando seu último contato com a civilização se afastar, pensei ser típico dos etnógrafos novatos. Os difíceis dias em La Pedrera me mostraram quanto minha formação acadêmica me preparou para lidar com a alteridade indígena exótica, e não com as alteridades da própria sociedade nacional.

Trago este relato individual porque, por um lado, mostra um complexo cenário histórico e cultural onde os atores envolvidos recorrem a lógicas diferentes, como se verá ao longo deste texto, e por outro, evoca em primeira mão a multidimensionalidade que a antropologia dedicada às fronteiras têm mostrado. Fronteira é um 
conceito polissêmico cuja função é conectar e separar, assemelhar e diferenciar e, por esse motivo, surge como uma construção histórica e cultural cujo leque conceitual é muito amplo, já que pode abranger desde ideias sobre o espaço e seu uso até configurações sociais e estados do ser. A diferença entre o português e o espanhol em que fronteira ou frontera serve para aludir a vários níveis de significado, na bibliografia em língua inglesa costuma se usar frontier para fronteira como frente de expansão econômica e cultural de uma sociedade nacional e de um estado, border para tratar da fronteira como limite territorial, jurídico e político entre estados, nações e populações distintas, e boundary para marcar a fronteira simbólica, social ou cultural, entre coletividades (Donnan eWilson, 1999; Grimson, 2000); no entanto, para alguns autores, não haveria diferenças significativas entre borders e boundaries, preferindo falar-se de borderlands como lugares de interação cultural, troca, criatividade e hibridação (Rosaldo, 1989; Diener e Hagen, 2010), e deixando borderlines para referir-se aos limites nacionais. A maioria das pesquisas antropológicas sobre fronteiras focalizam os temas de construção da nação, do estado, da identidade e da etnicidade (Barth, 2000 [1976]; Sahlins, 1989; Anderson, 1996; Donnan e Wilson, 1999, 2010; Wilson e Donnan, 1998; Grimson, 2000; Faulhauber, 2001; García, 2003; Cardoso de Oliveira e Baines, 2005; López, 2005; Diener e Hagen, 2010).

A ideia de fronteira é central para os estados nacionais porque circunscreve características sociais e culturais a um espaço onde supostamente se constrói um projeto identitário coletivo baseado numa história, numa cultura e numa língua comum. Assim, toda identidade nacional é diferente das outras e, por isso, a fronteira delimita para unir e diferenciar para além dela, uma vez que o estado-nação se pensa como uma unidade monolítica orientada por todas as características geográficas, sociais, linguísticas, políticas e culturais usadas para construir tal identidade nacional comum. Porém, na prática, a construção de um estado-nação entra em conflito com a própria composição da população nacional, que raramente é homogênea em termos étnicos, raciais, culturais, sociais, linguísticos ou religiosos, entre outros; portanto, há também fronteiras e alteridades internas que, em muitos lugares, coincidem com as fronteiras nacionais. Como o estado-nação precisa se consolidar internamente para cristalizar seu projeto unitário e expandir sua soberania, usa o poder de diferentes maneiras para impor ou negociar seu projeto de identidade nacional comum perante os grupos que se reconhecem com uma identidade coletiva diferente.

De acordo com Thomas M. Wilson (2000), a projeção que o Estado faz da "sua 
própria" cultura nacional pode ser contraditória com a experiência vivida por parte da sua população; por isso, é um erro pensar que as diversas culturas internas convergiriam numa cultura nacional, principalmente nas áreas fronteiriças onde o panorama cultural pode transcender à linha demarcatória. Como a construção histórica da fronteira é um processo arbitrário, sujeito a mudanças e reconfigurações ao longo do tempo, as populações dessas áreas devem fazer múltiplos arranjos, como, por exemplo, instrumentalizar e multiplicar as identidades segundo os contextos das relações sociais, já que a identidade é situacional (Barth, 2000 [1976]; Cardoso de Oliveira, 1976) e adaptar-se a condições muitas vezes desfavoráveis.

Como algumas regiões de fronteira são de difícil acesso para os agentes estatais, o processo de construção do estado-nação pode adotar inúmeras faces: nalguns casos, conflitos locais específicos podem nacionalizar-se gerando diferenças dentro de um mesmo grupo (Sahlins, 1989), inclusive, inviabilizando a manutenção das relações sociais; em outros casos, os estados ignoram as necessidades das populações e as forçam a viver situações de exclusão, discriminação e sofrimento, de imposições ideológicas que privilegiam um único processo civilizatório, de friç̧ão interétnica (Cardoso de Oliveira, 1996 [1964]), ou de violência exacerbada, por exemplo. No entanto, isto não significa que as populações fronteiriças aceitem passivamente as situações onde são colocadas pelos processos de construção dos estados nacionais, e não recorram a diversas estratégias de acordo com seus interesses particulares e seus modos próprios de entender e construir relações.

Deste modo, a fronteira surge como um lugar privilegiado para analisar vários temas: os mecanismos e dispositivos que usam os estados nacionais nas suas tentativas de autoconsolidação, a formação de identidades, os recursos criativos e a resiliência dos povos para lidar com as forças esmagadoras dos estados, pois, como bem afirma Alejandro Grimson (2000), as fronteiras são processos e estão em permanente construção. De especial importância para este trabalho é o estudo dos modos como um mesmo povo indígena ou povos muito próximos de regiões fronteiriças na Amazônia reagem às ações historicamente localizadas de dois estados diferentes porque, de um lado, permite elucidar aspectos típicos de como as diferentes nações amazônicas usam os índios como artefatos ideológicos na conformação dos seus indigenismos (Ramos, 1998) e, de outro, evidenciam os modos indígenas de lidar com a disparidade de forças entre eles e os estados.

Ao falar desses modos indígenas de lidar com os estados, refiro-me a diferentes formas de viver e estar no mundo, a construções diversas do espaço e do tempo, 
a outras estruturas sociais e formas de produção cujos valores estão distantes das dos estados, e que ressaltam características, como a fluidez das identidades e das relações sociais, o multilinguismo, a autonomia local, o autogoverno e a rejeição à concentração de poder. As lógicas indígenas são anti-estatais, ou melhor, como diria Pierre Clastres (2003 [1974]), contra-o-estado. Assim, a região de fronteira é, como afirma James C. Scott (2009), um espaço não estatal, um lugar onde para o estado é particularmente difícil se estabelecer e manter sua autoridade; por isso, na instigante expressão deste autor, "a etnicidade e a "tribu” começam onde a soberania e os impostos terminam” (:xi). A isto poderíamos acrescentar, como afirma João Pacheco de Oliveira (2016), que, para as estruturas e práticas estatais, as fronteiras são espaços de guerra permanente e negação de direitos.

Tendo estas ideias fundamentais em mente, neste texto detenho-me a uma parte da área fronteiriça entre a Colômbia e o Brasil que tem sido pouco trabalhada na bibliografia: o alto rio Tiquié e o baixo rio Pirá Paraná, onde habitam vários povos falantes de línguas tukano orientais. Este último rio fica totalmente na Colômbia e o primeiro nasce e corre cerca de 50 quilômetros neste país e continua a maior parte do seu curso em terras brasileiras. Embora ambos os rios estejam localizados em bacias hidrográficas diferentes - o Tiquié na do Uaupés/Negro e o Pirá Paraná na do Apapóris / Caquetá-Japurá - os habitantes desta área comunicam-se pelas cabeceiras dos afluentes destes rios. Desde poucos anos atrás, nesta região ocorre um processo de reaproximação entre os povos de ambos os lados da fronteira, pois o processo histórico de construção dos estados nacionais colombiano e brasileiro e de formação da fronteira os distanciou desde o final do século XIX. Para ilustrar como o processo histórico da construção dos estados nacionais afetou as relações entre os habitantes de ambos os rios, focalizo aqui as relações entre os índios Makuna do Pirá Paraná e os Tuyuka do alto Tiquié. Para isto, tratarei a fronteira tanto como um espaço não estatal quanto como um espaço em processo de construção dos estados colombiano e brasileiro. Desta forma, busco aproximar-me a alguns elementos das lógicas indígenas, mostrando como a presença de estados diferentes atingiu estes povos e as maneiras como estes responderam de acordo com cada contexto nacional e como, em anos recentes, os índios têm aproveitado alguns processos das suas relações com os estados para reconstruir as relações que a fronteira interrompeu durante mais de um século. 


\section{O espaço estatal: uma breve história da fronteira colombo-brasileira}

A fronteira internacional entre Brasil e Colômbia tem uma extensão aproximada de 1.645 quilómetros e localiza-se completamente na floresta amazônica. A fronteira atual foi delimitada pelo Tratado de Bogotá de 1907 e pelo Tratado Complementar de Limites e Navegação Fluvial de 1928 (Londoño Paredes, 1973). No Brasil, esta área é conhecida pelo apelido de “cabeça do cachorro”, já que, se olharmos o mapa com atenção, percebemos uma série de recortes espaciais onde se sucedem porções de cursos dos rios, divisores de águas e linhas imaginárias que terminam dando esse curioso formato, visto do lado brasileiro. Os rios Tiquié e Pirá Paraná localizam-se na altura do que seria o "queixo" da "cabeça do cachorro", e do ponto onde esta termina, na foz do rio Apaporis, parte uma longa linha reta imaginária em direção ao sul que chega até o rio Solimões. Este limite é conhecido como "linha Apaporis-Tabatinga", justamente a região mais pesquisada sobre esta fronteira (ver Zárate, 2008; López, 2014). Este limite fez parte das complexas negociações fronteiriças entre Brasil, Peru, Equador e Colômbia até que, depois da breve guerra de 1932, entre peruanos e colombianos, foi reconhecida definitivamente como colombiana pelo Protocolo do Rio de Janeiro de 1934, o qual ratificou a paz entre os dois países e os limites acordados por eles no Tratado Lozano-Salomón de 1922.

A disputa por esta região existe desde os tempos coloniais porque, desde os Tratados de Madri (1750) e de São Idelfonso (1777), a fronteira entre a Coroa espanhola e a Coroa portuguesa sobre o rio Solimões/Amazonas foi delimitada na desembocadura mais ocidental do rio Caquetá/Japurá, ponto que demarcava as terras espanholas a oeste (Gómez, 2014), mas, na prática, nunca foi aceito por Portugal, que estabeleceu como limite imperial o forte de Tabatinga, em território juridicamente espanhol. Além disso, os portugueses propunham a existência de um suposto canal que, como o Casiquiare, comunicaria as bacias dos rios Negro e Japurá e, com isso, aproximar-se-iam dos Andes. Para resolver as dúvidas, as duas Coroas decidiram enviar a quarta Comissão de Limites, em 1782, com o propósito de definir claramente a fronteira. O registro dos eventos ocorridos durante a quarta Comissão foi feito pelo coronel e engenheiro militar espanhol Francisco de Requena, que comparou o modo de agir dos espanhóis e dos portugueses para com as populações indígenas, colocando em destaque os supostos bons tratos dados aos índios por parte dos missionários castelhanos em oposição à insensibilidade portuguesa com seus cativos indígenas. De sua posição de oficial colonial, Requena (1992 [1782]) defendia os interesses de seu rei e assinalava continuamente as violações e 
abusos contra os limites fronteiriços cometidos pelos lusitanos, como a transferência de pessoas e a fundação ilegal de povoações no lado espanhol, informações verazes como pode se ver no Diário de viagem do sargento mor Henrique João Wilckens (1994 [1781]), segundo comissário português da quarta Comissão de Limites.

Segundo Requena, a partida portuguesa da quarta Comissão estava muito melhor preparada que a espanhola, porque tinha astrônomos e engenheiros, o que lhes proporcionava certas vantagens. O que não sabia o comissário espanhol era que a melhor preparação dos portugueses vinha do seu bom conhecimento geral da região, como se depreende, principalmente, dos relatos do padre Monteiro de Noronha (2006 [1768]) e do ouvidor Ribeiro Sampaio (1985 [1774-1775]) e que já especulavam sobre a existência do canal, mas também dos seus relacionamentos com os indígenas, já que, pelas alianças com vários grupos, fundaram-se vilas na área desde a segunda metade do século XVIII. Poucos anos depois da quarta Comissão que, aliás, não chegou a nenhuma conclusão nem rendeu um novo tratado de limites, houve mais explorações portuguesas em busca do canal.

Após as viagens do coronel Manoel da Gama Lobo D’Almada, entre 1784 e 1787, demostrou-se que o canal não existia e registraram-se vários caminhos que alternavam água e terra pelos quais era possível unir as bacias dos rios Negro e Japurá (Reis, 2006 [1940]). Os espanhóis nunca estiveram presentes nessa região, enquanto os portugueses e seus aliados indígenas incursionaram por ela para capturar escravos desde a metade do século XVIII, fomentando epidemias, guerras intertribais, descimentos e fundações de aldeias. De fato, o famoso naturalista Alexandre Rodrigues Ferreira (1983 [1787]) comentou que os índios Koretu e Müküna, que viviam no Apaporis, solicitaram às autoridades portuguesas a presença de vigários e soldados para acompanha-los nas aldeias que estavam construindo e pediam para não enviarem diretores, ${ }^{1}$ dos quais já conheciam as práticas violentas como cruéis administradores dos trabalhos dos nativos. Esta diferença na presença de agentes estatais de ambas as Coroas na região é fundamental para entender também as continuidades na história da disputa por esta fronteira, já que os portugueses usaram o princípio jurídico do uti possidetis de facto contra o uti possidetis de jure usado pelos espanhóis. Nos séculos posteriores, estes argumentos foram usados, ou melhor, herdados por brasileiros e colombianos para discutir os limites entre os dois países e sempre o argumento do uti possidetis de facto, usado por portugueses e brasileiros, teve maior peso.

As mudanças produzidas nas estruturas estatais com a independência da Repú- 
blica da Nova Granada, posteriormente República da Colômbia, e a formação do Império do Brasil nas primeiras décadas do século XIX não mudaram em nada a situação da fronteira quanto à presença de agentes estatais, e a violência continuou contra os indígenas, pois os brasileiros deram continuidade às práticas escravagistas dos portugueses. Alguns diretores tornaram-se comerciantes e obtiveram controle político e econômico em toda a região do Rio Negro, e se aliaram a soldados e policiais dos fortes da região (São Gabriel, Marabitanas, Cucuí) e de destacamentos militares, como o de Ipanoré, missionários e regatões (Meira e Pozzobon, 1999). Como se pode ver, houve do lado brasileiro muitos agentes estatais que pressionaram violentamente os índios e estes reagiram por meio de vários movimentos messiânicos no Alto Rio Negro, durante a metade final do século XIX (Wright, 2005).

A preocupação de limitar a fronteira surgiu também na segunda metade do século XIX, quando os dois países decidiram firmar um Tratado de Amizade e Limites e uma Convenção de Navegação em 1853. O Tratado nunca foi ratificado e foi preciso aguardar até 1907 para a definição dos limites entre ambas as nações. Contudo, as negociações de 1853 retomaram discussões da quarta Comissão que ajudaram a concretizar a linha Apaporis-Tabatinga, assim como esboçaram algumas cessões territoriais possíveis pela pretensão colombiana de ter acesso ao Solimões / Amazonas. O Ministro Plenipotenciário brasileiro lotado em Bogotá apresentou um documento assinado pelo Presidente da Província do Amazonas, onde comprovava a presença, em Manaus, de 23 tuxauas com seus diretores, convocados da enorme região compreendida entre o rio Içá/Putumayo e o Alto Rio Negro, para legitimar pelo uti possidetis a ocupação do território demonstrada pela submissão dos índios ao Império, graças às relações de longa data, anteriores às Declarações de Independência (Exposición sobre el Tratado de Límites de 1853: 26). Por sua vez, como prova de boa vontade e amizade, o Brasil aceitou marcar a fronteira no rio Apaporis - algo que os comissários portugueses da quarta Comissão não queriam fazer por causa das suas pretensões de chegar até os Andes - e com isso conseguiram que a fronteira sobre o Caquetá/Japurá fosse a foz do Apaporis, mudando os limites coloniais. Desde a foz do Apaporis, seguindo em direção norte, tomou-se como fronteira todo o curso do rio Traíra, um dos seus afluentes, e desde sua cabeceira se traçou uma linha reta imaginária que vai até a confluência do rio Papurí com o Uaupés. Desta forma, ficou delimitada a área de fronteira focalizada neste artigo.

Até o início do primeiro auge da borracha, em 1870, os povos tukano de ambos os lados da fronteira viveram um contato semelhante e sofreram, com intensidade 
variada, a presença dos portugueses e dos brasileiros, pois os colombianos só entraram definitivamente em cena no começo do século XX com a chegada dos caucheros que, muitas vezes, também atuaram como agentes consulares e aduaneiros (Zárate, 2008). Por isso, na primeira década do século XX, instalaram-se os primeiros postos aduaneiros colombianos em La Pedrera, perto da foz do Apaporis e em Yavareté, lado colombiano da foz do Papuri, constituindo os primeiros atos de soberania nacional do estado colombiano na região. A exploração da borracha e as ações dos seringueiros e caucheros exacerbaram a violência e a exploração contra os índios, que tomou a forma de genocídio na fronteira colombo-peruana pelas ações da sanguinária Casa Arana. ${ }^{2}$ Para conter a possível expansão de Arana até o Caquetá, tentou-se fortalecer militarmente La Pedrera em 1911, mas a vila foi invadida no mesmo ano pelos peruanos e rapidamente devolvida a Colômbia, após protestos diplomáticos. Na época, como bem ilustra Carlos Zárate (2008), a presença estatal da região estava em mãos dos caucheros e dos cônsules em Manaus e Rio de Janeiro; estes últimos recebiam cartas dos caucheiros sobre o que acontecia na região para transmitir as informações ao governo em Bogotá. Afinal, em várias situações, os cônsules e os caucheros partilharam negócios e a realidade da exploração indígena dificilmente chegava aos ouvidos do governo central.

A existência da fronteira foi irrelevante durante o primeiro auge da borracha, já que, principalmente brasileiros, colombianos e peruanos atravessavam os limites territoriais para apresar os índios, cometendo um sem número de atrocidades, com a conivência das diferentes presenças estatais. Relatos de etnólogos como Theodor Koch-Grünberg (1995 [1909]) e Curt Nimuendajú (1982 [1927]) e de exploradores como Gordon MacCreagh (1990 [1926]) e William McGovern (1927), que viajaram pela região nas primeiras décadas do século XX, confirmam o clima de pânico e belicosidade que os índios sentiam pela presença de brasileiros e colombianos. Com o declínio do primeiro auge da borracha por volta de 1913, as ações violentas dos brancos deram trégua por alguns anos, embora mantivessem atividades extrativistas de balata e outras gomas.

Em 1914, os missionários salesianos iniciaram suas ações no Alto Rio Negro e instalaram missões com internatos, de acordo com Aloísio Cabalzar (1999), em São Gabriel do Rio Negro em 1914, Taracuá perto da foz do Tiquié em 1923, Iauareté na confluência do Papuri e Uaupés em 1929, e em Pari-Cachoeira no rio Tiquié em 1940, tornando-se mais influentes sobre os índios do que os comerciantes e seringueiros. No lado colombiano, os missionários monfortianos também se instalaram 
na região do Uaupés, em 1914, especialmente nos rios Papuri e Cuduyari, para fundar missões e escolas (Cabrera, 2002). Os missionários se dedicaram a atacar os rituais indígenas e as malocas, até que conseguiram erradicá-las nas suas áreas de influência. Isto não aconteceu na região do Apaporis e do Pirá Paraná. Em La Pedrera, a presença missionária começou na década de 1930 com a fundação de um internato, e os missionários não tiveram presença permanente no Apaporis e no Pirá Paraná, rio onde se estabeleceram primeiro os missionários protestantes do Summer Institute of Linguistics (SIL), depois de 1960, e onde se instalaram um par de internatos católicos poucos anos mais tarde. Nesta região, a formação de aldeias começou na segunda metade da década de 1970 e nunca se deixou de construir malocas para celebrar os rituais.

A. Cabalzar (1999) afirma que, até a chegada dos salesianos, a presença missionária no Alto Rio Negro nunca foi permanente e oscilou entre longos momentos sem influência e curtos períodos de interferências intensas. As marcas dos salesianos ainda são profundas devido à intensidade com que implementaram seu "projeto civilizador" mediante a educação de crianças e jovens nos internatos, com a intenção de transformar os índios em cristãos e brasileiros. Os salesianos foram agentes a serviço do estado brasileiro e, a partir da década de 1930, tiveram reforço com a instalação de postos do Serviço de Proteção aos índios (SPI) em Iauaretê (Andrello, 2006) e em outros pontos da fronteira (Papuri e Cuduyari) para proteger os índios do aliciamento de mão de obra pelos caucheros colombianos e, desde finais da década de 1950, receberam apoio da Força Aérea Brasileira. Com o passar do tempo, a presença salesiana levou à criação de numerosos aldeamentos pela região inteira. A influência dos missionários começou a decair na década de 1980, quando o Projeto Calha Norte instalou pelotões de fronteira em vários pontos da região e, na atualidade, a presença de agentes estatais se multiplicou. Desde a nova constituição de 1988, têm-se formado mais de cinquenta organizações indígenas locais e uma federação regional que tem ganho visibilidade e peso político, pois suas autoridades influenciam a política municipal em São Gabriel da Cachoeira e se relacionam diretamente com as instituições de governo em Manaus e Brasília.

Do outro lado da fronteira, o projeto do estado colombiano de usar os missionários como agentes estatais não chegou até o Apaporis, por isso, durante as primeiras décadas do século XX, os únicos agentes estatais foram os caucheros que agiam a seu bel-prazer, explorando a mão de obra indígena, organizando casamentos e rituais, tornando-se parentes dos índios pelos matrimônios com mulheres indígenas. É jus- 
tamente nesta época que a fronteira entre as duas nações começou a produzir efeitos diversos para os tukanos dos dois países, pois os povos do lado brasileiro viram-se imersos num processo de coerção diferente da dos índios do lado colombiano que ficaram no Apaporis e Pirá Paraná: enquanto do lado colombiano eles ficaram expostos à violência e aos abusos dos caucheros, do lado brasileiro, tiveram nos missionários um escudo protetor contra os maus tratos dos seringueiros, mas sofrendo ataques violentos à sua forma de vida. Os salesianos dedicaram-se à catequese e à educação (ensino do português, por exemplo), mas também se empenharam em atacar os xamãs e a vida ritual dos índios, obrigando-os a vender ou destruir seus ornamentos cerimoniais, a abandonar seus rituais e renunciar à vida nas malocas. Os Tukano do lado colombiano que sofreram com os monfortianos passaram por situações semelhantes, embora o projeto destes missionários fosse de menor fôlego que o dos salesianos, que tiveram "o aval oficial e verbas públicas que lhe permitiriam construir uma eficiente empresa “civilizadora'” (A. Cabalzar, 1999: 368). Enquanto isso, os Tukano que ficaram sob o poder dos caucheros sofreram com a exploração da sua mão de obra, mas conseguiram conservar suas malocas, ornamentos cerimoniais e a maior parte dos seus rituais. As violências do tempo da borracha e as empreitadas missionárias conseguiram desarticular parte das relações sociais de vários grupos e famílias que, pela conjuntura histórica e pelas decisões que tomaram para lidar com os agentes de ambas as nações, escolheram ficar de um lado ou outro da fronteira num momento determinado. Com os anos, o crescimento urbano de Mitú, na Colômbia, e de São Gabriel da Cachoeira, no Brasil, permitiu um trânsito mais intenso dos índios nas cidades e muitos terminaram migrando até cidades mais distantes, como Manaus, Letícia, Brasília e Bogotá.

Na década de 1940, um novo auge da borracha atingiu os índios do Apaporis e do Pirá Paraná e as dívidas do sistema de aviamento foram mais eficazes do que a coerção violenta. Nas décadas seguintes, houve outros picos extrativistas, inclusive de cocaína nos anos 1980, e chegaram novos atores da sociedade nacional colombiana como autoridades civis, comerciantes e pesquisadores cujas ações erodiram a influência dos velhos patrões e dos religiosos. Em 1991, uma nova constituição foi aprovada na Colômbia e reconheceu direitos que levaram à organização de Associações de Autoridades Tradicionais Indígenas (AATI's), que entraram em vários processos de diálogo com o Estado, principalmente em questões de ordenamento territorial, governo próprio, saúde e educação próprias. O resultado é que, na atualidade, as políticas indigenistas e o estatuto legal dos territórios indígenas dos dois países são 
bastante diferentes, mas a autonomia política permite aos índios criar alianças transfronteiriças, que conduzem a dialogar e retroalimentar suas posições e ações frente aos dois estados pelos interesses comuns sobre o território que partilham. Isto significa que, na conjuntura atual, os indígenas se apropriaram de elementos das lógicas estatais e os usam tanto para dialogar e reivindicar seus direitos dos estados como para fazer acordos entre organizações vizinhas do outro país com o objetivo de partilhar temas caros a seu próprio modo de entender o mundo e as relações.

\section{O espaço não estatal: território e relações entre os Makuna e os Tuyuka}

A região do Alto Rio Negro, entre as fronteiras do Brasil, Colômbia e Venezuela, é habitada por cerca de 30 mil indígenas de vinte e nove povos pertencentes às famílias linguísticas Arawak, Tukano Oriental, Nadahup, Kákua-Nukak e Karib. ${ }^{3}$ Esta é a área de maior diversidade étnica e linguística da Amazônia. A região tem sido objeto de inúmeras pesquisas antropológicas entre os Tukano ${ }^{4}$ desde o início do século XX. Estes trabalhos têm mostrado que estes povos constituem um complexo sistema regional aberto e multilíngue, onde os grupos estão articulados entre si por diferentes circuitos e redes de intercâmbio matrimonial, de objetos rituais e de cultura material, compartilhando também algumas características gerais de organização social (unidades exogâmicas patrilineares e segmentares organizadas hierarquicamente, residência patri/virilocal, terminologia de parentesco tipo dravidiano, a maloca como forma prototípica de assentamento, etc.) e o ciclo ritual baseado na utilização de flautas e trombetas sagradas durante a iniciação masculina, segmentos de narrativas míticas e alguns fundamentos cosmológicos que estruturam e definem o uso do espaço comum.

Os Makuna e os Tuyuka são dois povos falantes de línguas tukano orientais e têm uma população aproximada de 600 e 500 pessoas, respectivamente. Os primeiros habitam as partes baixas e os afluentes dos rios Apaporis e Pirá Paraná, convivendo neste último rio com os Yibá masã, Barasana, Taiwano, Tatuyo, Bará, Yuhup, e algumas famílias Tuyuka que migraram poucos anos atrás. Por sua parte, os Tuyuka vivem na região do alto Tiquié e partilham este rio com os Bará,Yibá masã, Tukano, Desana, Mirití-Tapuyo eYuhup. Os Tuyuka e os Makuna não se casam entre si e têm os Yibá masã como afins comuns.

A região das cabeceiras do rio Toaka, território tradicional makuna, e as do Komeña, território tradicional yibá masã, são próximas das do rio Tiquié, onde habitam alguns clãs de menor hierarquia tuyuka. Esta proximidade territorial per- 
mitia, no passado, que os Tuyuka e os Makuna se relacionassem de formas diversas, mas o processo histórico de construção dos estados nacionais brasileiro e colombiano conseguiu cortar parte da fluidez das suas relações durante várias décadas. Os Makuna trocavam tornozeleiras e veneno por ornamentos plumários e bastões de dança com os Tuyuka e os Tukano do Tiquié (Århem et. al., 2004) e, pelo menos até o final do século XIX, convidavam-se mutuamente para a guerra (Koch-Grünberg, 1995 [1909]) e para participar de rituais.

No plano sociológico, podemos afirmar que os Tuyuka e os Makuna não se casam entre si porque ambos têm um mesmo grupo de afins, portanto, são co-afins, como afirma Aloísio Cabalzar (2008). Como a filiação é patrilinear e o sistema terminológico dos povos tukano orientais é dravidiano, o universo social se classifica em consanguíneos e afins. Por isso, os grupos que partilham os afins estão proibidos de se casar entre si e devem referir-se mutuamente com termos de consanguinidade. Os Tukano costumam referir-se a estas relações entre grupos co-afins com dois termos: irmão (mais velho/mais novo) e "filho de mãe" (hako maku. Mk; pakomaku. Ty). O último indica a proibição de casamento entre irmãos uterinos, filhos de pais de grupos diferentes (Cayón, 2013), e com os primos paralelos matrilaterais (A. Cabalzar, 2008). Como os filhos de uma única mulher ou de duas irmãs podem pertencer a grupos patrilineares distintos, é necessário proibir o casamento entre eles, o que implica a existência de uma categoria exogâmica mais ampla que a do grupo. Tal categoria exogâmica é a fratria, porém, não tem um nome específico nem engloba os grupos numa identidade comum.

Os Makuna e os Tuyuka fazem parte da mesma fratria e ambos consideram os Taiwano e Karapana como parte dela. No entanto, os primeiros estendem a fratria aos Letuama e Bará e os segundos aos Arapaso, Mirití-tapuya e Tariana. Em algumas versões que coletei entre os Makuna, afirma-se que os Tuyuka são irmãos mais novos e em outras se diz que são "filhos de mãe". Nas informações de A. Cabalzar, os Tuyuka afirmam que os Makuna são unicamente "filhos de mãe". Esta discrepância não é importante e aponta apenas as diferenças na maneira como se entende a origem destas relações, as quais têm a ver com variações associadas às narrativas de origem da humanidade e a distribuição dos povos pelos territórios nos tempos míticos. Isto é fundamental para compreender as ideias que eles têm sobre fronteiras territoriais e culturais.

Sem entrar em muitos detalhes, as narrativas tukano orientais relatam uma viagem ancestral vinda do Leste, onde uma Sucuri-Canoa ou um grupo de Sucuris 
ancestrais remontaram os rios até chegar a uma cachoeira considerada o centro do mundo. Ali os ancestrais humanos emergiram e se distribuíram pelos diferentes territórios, recebendo dos demiurgos os objetos cerimoniais e demais elementos essenciais à vida. Os Tuyuka originaram-se da Sucuri Pedra, os Makuna da Sucuri Água, os Taiwano e Karapana da Sucuri Remédio; explica-se que estas Sucuris ancestrais fizeram boa parte do seu percurso juntas, separando-se em alguns lugares do Pirá Paraná. Desses lugares, as Sucuris se encaminharam para os territórios onde deixaram seus descendentes. Cada povo, então, tem uma narrativa única que inclui o percurso do seu ancestral juntamente com os ancestrais dos povos com os quais partilham sua fratria, mas enfatiza o percurso exclusivo do próprio ancestral, que sempre culmina com a entrega do território.

Todas essas narrativas descrevem a origem e a história comum dos grupos e sua diferenciação, dando ênfase à relação entre origem, território e identidade. Na lógica indígena, todos os lugares pelos quais passaram as Sucuris ancestrais juntas formam parte de um território comum a todos os grupos, enquanto que os espaços que cada Sucuri percorreu individualmente correspondem ao território específico de cada grupo, chamado de sita goro (terra própria). Os percursos das Sucuris estão codificados numa linguagem erudita chamada keti oka (Mk) ou bahsere (Ty) e fazem parte do repertório de conhecimentos exclusivos que tem cada grupo juntamente com outra série de posses materiais e imateriais, como as flautas sagradas usadas nas iniciações masculinas, a caixa de ornamentos plumários, um conjunto de nomes secretos, danças, cantos e encantamentos, a língua, variedades de mandioca, tabaco, coca e frutas cultivadas, direitos para usar e fabricar certos objetos e grafismos, entre muitas outras coisas que são centrais para construir uma identidade coletiva. Cada repertório de conhecimentos é fundamental para o manejo do território que contempla tanto a prática e a ética no uso dos diferentes recursos como uma série de complexas relações sociais com os espíritos que são donos dos diversos lugares nomeados do território. Estas relações são gerenciadas pelos kumua (xamãs ou sabedores) e implicam, entre outras coisas, a repetição mental das viagens das Sucuris ancestrais. Por isso, afirmam os Makuna, os kumua, trabalham e viajam com seu Pensamento.

Assim como cada povo define um território próprio (sita goro), sabe que, quando entra no de outro povo, deve seguir certas regras de comportamento para que não haja problemas nem com os parentes e cunhados nem com os espíritos donos dos lugares, pois estes enviam doenças quando se faz uso dos seus lugares sem autorização. Não é proibido pescar ou caçar no território de outros grupos, mas é de bom 
tom pedir permissão aos donos de tal território.

Maximiliano García, um destacado líder makuna, costuma dizer que os índios nunca brigam por um pedaço de terra e não discutem se alguém pode passar ou entrar em determinado espaço que não lhe corresponde, porque todos sabem respeitar: se ao passar por outro território uma pessoa sente fome, não toma nada dos lugares com espíritos donos, não caça ou pesca em excesso, não derruba árvores; apenas pega o que precisa. Agora, se quiser abrir uma roça ou morar num outro território, precisa pedir autorização e terá que aprender as recitações de keti oka adequadas para poder morar ali. Por isso, a ideia de fronteira como um limite intransponível não existe entre os Tukano orientais, embora digam que a fronteira entre um território e outro fica em tal rio; para referir-se a um limite do seu território, os Makuna usariam a expressão ide masã sita susarihi (limite da terra da Gente Água) e se for dos Yibá masã, por exemplo, diriam Yibá masã sita susarihi (limite da terra dos Yibá masã).

Estes limites são físicos e também são enunciados nas narrativas de keti oka, pois os percursos mencionados nessas narrativas indicam pontos de encontro e/ou separação. Embora um povo tenha um rio próprio, é comum existirem lugares dentro do seu território que pertencem a outros grupos de consanguíneos ou de afins, porque alguma das Sucuris ancestrais ou algum dos primeiros humanos associados a tal grupo viveram uma história naqueles lugares. Mais do que ser uma espécie de consulado ou embaixada, esses lugares servem para tornar possível curar a alimentação e as doenças de uma pessoa que seja de outro povo, mas que viva ou esteja de visita no território de outrem, algo muito comum, porque a residência é virilocal e, em geral, as mulheres vêm de fora e recebem visitas frequentes dos seus pais e parentes que, inclusive, podem se instalar permanentemente no território dos seus afins. Outros limites das narrativas keti oka ficam nos lugares que são partilhados por vários povos e que estão relacionados com as viagens das Sucuris ancestrais; costumam ser grandes cachoeiras e morros de importância coletiva e, portanto, devem ser cuidados por todos os grupos, já que todos têm a obrigação de cuidar do grande território comum. Para isso, usam a expressão "manejar o mundo", que significa tanto aplicar seus conhecimentos de keti oka/bahsere como usar os recursos de acordo com certas regras práticas e morais (ver Cayón, 2013). Ninguém mora nesses lugares e alguns deles funcionam como pontos de encontro mental dos kumua de vários grupos, assim como limites finais dos percursos que fazem com suas recitações e pensamentos. 
Por haver lugares comuns a todos os povos e locais particulares de algum grupo dentro do território de outro, não se entende o espaço como uma entidade fechada e circunscrita, pois ele não é exclusivo de um povo, é também partilhado com outros seres não humanos, havendo lugares que são pontos de conexão e relação com outros grupos de consanguíneos e afins. Em vez de unidade territorial e linguística, há multiplicidade; em vez de uma lógica de dominação e coerção, há uma lógica da persuasão, equivalência, partilha e respeito mútuo; em vez de uma lógica de soberania, há uma lógica de "propriedade coletiva”. As ideias de território e fronteira dos Tukano orientais não são excludentes, ao contrário, são fluidas e contra a lógica do Estado.

\section{Restaurando as relações: assumir a lógica estatal para manter o espaço não estatal}

No começo do século XX, os patrões seringueiros e os comerciantes do Rio Negro faziam expedições punitivas contra as aldeias do Tiquié e os Tuyuka tentavam permanecer distantes nas cabeceiras do rio, enquanto a chegada dos caucheros colombianos e os boatos sobre uma deportação iminente fizeram com que a maior parte dos Makuna saísse do rio Toaka e se escondesse no rio Popeyaka, um afluente do Apaporis, que é o território dos Letuama, enquanto o resto ficou no rio Komeña, vivendo com seus cunhados Yibá masã. Temerosos, os índios se afastaram dos cursos principais dos rios e tentaram se refugiar em regiões isoladas, pois a violência e a coerção se intensificaram. Nenhum grupo esteve a salvo da exploração da borracha: os Makuna e os Letuama foram aliciados pelos caucheros e levados para trabalhar no rio Mirití Paraná, um afluente do Caquetá/Japurá, alternando temporadas nos acampamentos com a vida "normal" no Popeyaká, onde conseguiam plantar suas roças e realizar parte das suas festas. Os Makuna saíram desse rio no começo da década de 1960, ficando meio século longe do seu território tradicional, afastados dos seus cunhados e parentes do Pirá Paraná, sem usar suas flautas sagradas, e cerceada a transmissão de todos os conhecimentos sobre o manejo do território, dos mais velhos aos mais jovens.

Uma vez livres do jugo dos patrões no começo dos anos 1960, os descendentes da geração que passou décadas coagida pelos caucheros e que apenas conhecia suas terras pelas memórias dos mais velhos, decidiram voltar para casa, construir malocas e retomar seus rituais. A tentativa de retornar ao rio Toaka e Pirá Paraná não foi totalmente bem-sucedida, porque houve uma dispersão. Vários membros 
do grupo ficaram no Apaporis, aqueles que tinham filhos no internato foram para La Pedrera e alguns migraram mais tarde para Leticia. Com a construção de pistas de pouso e a fundação de internatos católicos no Pirá Paraná nos anos 1970, alguns makuna saíram da região e se instalaram em Mitú. Dessa forma, além de orientar sua vida em torno das relações sociais no Pirá Paraná e Apaporis, os centros urbanos mais próximos, como Mitú e La Pedrera, converteram-se em lugares centrais para conseguir mercadorias por meio de visitas aos parentes e de trabalhos remunerados e, com o passar dos anos, para receber atendimento médico, avançar na formação escolar e interagir com lideranças de outros povos e com as autoridades departamentais e nacionais. Em muitos casos, aqueles que ficaram e ainda moram no Pirá Paraná e Toaka são os membros da mais alta hierarquia dos clãs que, além disso, têm as maiores responsabilidades rituais e políticas.

Do lado brasileiro no alto Tiquié, os salesianos conseguiram extirpar a última maloca dos Tuyuka, no começo de 1960, e praticamente ninguém conseguiu livrar-se da educação escolar dos missionários. As caixas de ornamentos rituais também foram destruídas, impossibilitando a realização de rituais importantes e, com a perda da maloca e em detrimento das aldeias, as relações intrafamiliares e intragrupais sofreram sensíveis mudanças. Na férrea disciplina salesiana, os horários eram rígidos, as crianças eram separadas por sexo e eram impedidas de conviver entre si e de falar qualquer língua indígena, embora, com o tempo, o tukano tenha se convertido em língua franca nos internatos. Porém, quando a influência salesiana diminuiu, os Tuyuka rapidamente começaram a retomar suas tradições. A. Cabalzar (1999) explica que as malocas tuyuka sobreviveram do lado colombiano do alto Tiquié e, nesse sentido, a fronteira serviu para deter o efeito destrutivo dos salesianos. Nessa área, como também mostra o trabalho de Flora Cabalzar (2010), a vida de várias pessoas transcorreu alternando localidades em ambos os lados da fronteira, de acordo com as conjunturas e escolhas que tiveram que fazer, tendo sempre os conhecimentos adequados para se relacionar com as autoridades de ambos os países. Para estas pessoas, a existência de uma fronteira nacional no seu território nunca os impediu de percorrer e habitar diferentes porções deste território tradicional e de se adaptar a diferentes contextos. Uma mesma pessoa poderia durante a vida ter passado pelo internato salesiano, trabalhado no Brasil e na Colômbia, habitado tanto em malocas do lado colombiano como em aldeias do lado brasileiro e, inclusive, em cidades como Mitú ou São Gabriel da Cachoeira. Embora nos momentos de maior opressão dos agentes estatais as relações sociais, as cerimônias e 
a mobilidade fossem limitadas, a lógica indígena permaneceu e conseguiu se adaptar a situações adversas.

Nas décadas de 1970 e 1980, alguns dos alunos que foram formados nas escolas salesianas tornaram-se professores, transformaram-se em críticos da empresa missionária e a enfraqueceram, ao mesmo tempo que denunciaram os problemas gerados pelos empreendimentos desenvolvimentistas do Estado brasileiro. Com o apoio de setores progressistas da Igreja católica e de ONGs indigenistas e ambientalistas, os líderes indígenas iniciaram organizações de base e começaram a discutir questões regionais para dar origem à Federação das Organizações Indígenas do Rio Negro (FOIRN), em 1987 (Martelli Soares, 2012), ganhando cada vez mais peso político e autonomia, graças às mudanças promovidas pela Constituição de 1988 . Abandonados os postulados centenários da assimilação e da tutela, o Estado brasileiro reconheceu direitos aos indígenas, às suas culturas e territórios. A demarcação das Terras Indígenas e o reconhecimento dos direitos levaram os Tuyuka a um processo de recuperação de conhecimentos e da língua, muito enfraquecida pela hegemonia do tukano. Dessa maneira, os professores das pequenas escolas existentes em algumas aldeias do alto Tiquié juntaram-se e, em 2001, organizaram a Associação Escola Indígena Utapinopona Tuyuka (AEITH), uma escola única para os Tuyuka, que conta com a assessoria da ONG Instituto Socioambiental. Surgiram, no mesmo rio, outras Associações Escola que atuam de maneira semelhante à Escola Tuyuka.

Na Colômbia, os índios do Apaporis e do Pirá Paraná começaram a fundar aldeias na década de 1970 e se relacionavam com os agentes estatais por meio de “capitães", muitos deles escolhidos pelos velhos caucheros e missionários. A formação de organizações políticas resultou diretamente das mudanças promovidas pelo Estado com a Constituição de 1991. Deixando para atrás o projeto de uma nação hispânica e católica composta por uma população homogênea, de caráter mestiço, que considerava os índios como "inferiores" e "selvagens" obrigados a "civilizar-se", a Colômbia passou a definir-se como um país pluriétnico e multicultural que reconheceu os direitos territoriais e de cidadania plena dos índios, assim como a autonomia das suas formas de governo e de vida. Uma das propostas mais sofisticadas postula o reconhecimento dos territórios indígenas sob o nome de Resguardos, com propriedade coletiva e inalienável, sendo também impenhoráveis e imprescritíveis. Dentro desses territórios, reconhece-se a jurisdição das autoridades indígenas em tudo que está relacionado ao uso do solo, proteção ambiental, povoamento, elaboração de planos de desenvolvimento econômico e social, aplicação de recursos, etc. 
Este seria um primeiro passo para cumprir o objetivo de que cada Resguardo se transforme numa Entidade Territorial Indígena (ETI), figura político-administrativa, que reconhece aos índios o governo dos seus territórios por meio das suas autoridades tradicionais, equivalente a outras jurisdições territoriais, como municípios ou departamentos, e que recebe recursos econômicos diretamente do Estado para seu funcionamento. Isto implica que as ETI's devem se integrar como novas formas organizativas da nação e às autoridades indígenas seriam transferidas funções estatais de controle territorial. Os primeiros passos nessa direção deram origem, em 1995, à Asociación de Capitanes Indígenas del Pirá Paraná (ACAIPI).

A formação das organizações indígenas AEITH e ACAIPI respondeu a novas conjunturas criadas pelos estados nacionais. Em vários sentidos, estas organizações têm um fundo estatizante, já que estão orientadas para dialogar com os Estados nos termos impostos por estes, inclusive, no caso colombiano, para gerenciar recursos econômicos. Da mesma forma, a estrutura interna, os cargos, a rotatividade das diretorias e suas escolhas pelo voto são influenciados por estruturas estatais e mecanismos ditos democráticos, alheios às formas organizativas indígenas. No entanto, os índios conseguem adaptar tais estruturas e fazer as coisas ao seu modo. A organização da ACAIPI é hierárquica, com os kumua e donos de maloca no topo, seguidos por cantores dançadores e outros sabedores tradicionais, depois por homens e mulheres adultos e, finalmente, pelos representantes da organização. Esta conta com presidente, tesoureiro, secretário de saúde, secretário de educação, etc. Supõe-se que as decisões tomadas pela Assembleia de autoridades tradicionais sejam executadas pelos representantes em suas visitas às instituições estatais regionais e nacionais.

Tudo isto é resultado de um longo aprendizado. No começo, ACAIPI teve que iniciar seus trabalhos juntando representantes de todos os povos, aldeias e malocas do Pirá Paraná, um rio com cerca de 250 quilômetros de extensão, e fazer diversas reuniões para entender o que o Estado colombiano queria deles. Com a ajuda da ONG Fundación Gaia Amazonas, captou recursos em vários países, iniciaram-se oficinas e reuniões dirigidas a pensar sobre o território comum e sua forma de vida. Assessorados por essa fundação, elaboraram mapas, organizaram comissões temáticas de educação, saúde, conhecimentos femininos e manejo ambiental, realizaram oficinas de trabalho colaborativo, etc. Em 2008, elaboraram um documento chamado Plano de Vida, onde apresentam ao Estado colombiano seu projeto de vida baseado no cumprimento do seu calendário ecológico próprio e descrevendo suas necessidades em educação, saúde, desenvolvimento econômico e governo próprio 
(Cayón, 2012). Assim, usando a linguagem que o Estado entende e apresentando o inventário de recursos naturais do território solicitado por ele - eufemisticamente chamado de Plano de Reordenamento Territorial -, os índios não propõem medidas radicalmente diferentes para o manejo que vêm desenvolvendo através de práticas tradicionais, como a horticultura, a caça, a pesca e as trocas xamânicas com os espíritos donos dos lugares. Com estes Planos, os índios fazem uma leitura da sua própria história e privilegiam seus sistemas de conhecimento. Advertem o Estado colombiano de que seu território já está ordenado desde o começo dos tempos e que são eles que sabem manejá-lo com seus conhecimentos, práticas e rituais. Frente aos entraves burocráticos que as entidades estatais lhes colocam no que tange a educação, a saúde e o manejo ambiental, eles asseveram, nas palavras de um líder da região "que as coisas devem ser feitas daqui para lá, e não de lá para cá. Por isso eu digo que nós fazemos política anti-estado aqui”.

Assim como a ACAIPI se preocupa em manter sua forma de vida tradicional e ter a garantia da proteção do Estado ao território e melhores condições de educação e saúde, no Brasil a AEITU tem convertido a escola num projeto coletivo orientado para a recuperação dos seus conhecimentos, que vai até o Ensino Médio e conta com a assessoria do Instituto Socioambiental. Essa escola desenvolve currículos centrados numa pedagogia de pesquisa coletiva e aprendizado com projetos de longa duração e oficinas, com a participação tanto de especialistas brancos como de conhecedores tradicionais - às vezes convidados de comunidades do lado colombiano para ensinar cantos e benzimentos -, a elaboração de material pedagógico e publicações dos seus resultados. Os projetos, oficinas e produtos dessa escola são extraordinários e versam sobre assuntos linguísticos, matemáticos, musicais, arquitetônicos, culinários, artísticos e de artesanato, manejo agroflorestal, piscicultura, produção melífera, técnicas de pesquisa, edição gráfica, registro de áudio, entre outros (A. Cabalzar et. al., 2012). A Escola Tuyuka tem se convertido no principal espaço de recuperação e transmissão do conhecimento dos Tuyuka. O aparente paradoxo criado pelo fato de a escola, um espaço estatal por excelência, implantada pelos salesianos para erradicar os conhecimentos indígenas, ter se convertido no lugar que exalta esse mesmo conhecimento é uma poderosa evidência da profunda inteligência e sensibilidade indígena para redimir qualquer espaço estatal, transformando-o num espaço não estatal que enaltece as relações entre as gerações e a continuidade de uma forma singular de estar no mundo.

Desde 2003, AEITU tem feito trocas e intercâmbios de experiências (ver A. 
Cabalzar et. al., 2012). Dentre estes, destaco a realização dos encontros chamados Canoitas, que são um dos produtos da iniciativa CANOA (Cooperação e Aliança no Norte e Oeste Amazônico), um programa apoiado por organizações indígenas e não indígenas do Brasil, Colômbia e Venezuela com o objetivo de consolidar os territórios indígenas e as áreas de uma vasta região da floresta amazônica para preservá-la. Entre 2005 e 2006, organizaram-se duas Canoitas Tiquié (Brasil-Colômbia), quando os povos deste rio conversaram sobre a história e o manejo do território. Entre 2005 e 2014, celebraram-se seis Canoitas Tiquié-Pirá Paraná, algumas delas contando com a participação de outras organizações indígenas dos dois países. No entanto, na maioria dessa Canoitas participa o pessoal do Tiquié e do Pirá Paraná, e ali socializam as situações que vivem com os Estados brasileiro e colombiano, e partilham suas experiências de mapeamento e registro das histórias, entre outros temas, tendo como pano de fundo o fortalecimento da governança indígena sobre o território coletivo que está para além da fronteira. Alguns líderes afirmam não se importarem com a fronteira, porque o território é deles e seus limites não correspondem às linhas demarcatórias.

Como os encontros se realizaram em ambos os lados da fronteira, os participantes puderam conhecer diretamente as aldeias, malocas e escolas dos seus vizinhos para ver de perto seus pontos fortes e debilidades. Além de intercâmbios que propiciam reflexões, também podemos entender estes reencontros como oportunidades para refazer e atualizar as relações que seus ancestrais tiveram e que foram rompidas desde finais do século XIX pelos processos de construção da fronteira. Nas Canoitas, identificaram-se interesses comuns associados à proteção dos territórios, ao manejo ambiental e à educação escolar. A forma como se trabalham estes assuntos passa pela partilha de narrativas, cada povo na sua própria língua, explicando, por exemplo, como foram as viagens das Sucuris ancestrais, ou os modos como entendem o significado de certos lugares sagrados. Os índios do Pirá Paraná ficaram impressionados com as experiências da Escola Tuyuka e perceberam que, em questões de saúde, o Estado brasileiro estava muito mais presente do que o colombiano; por outro lado, preocupou-os a escassez de peixe noTiquié, a falta de especialistas rituais e a perda de certos conhecimentos tradicionais, como a celebração dos rituais de iniciação masculina e os benzimentos, associados ao manejo do ciclo anual. Então, em suas conversas, acharam importante restabelecer as trocas, mas agora centradas nos conhecimentos: os índios do Pirá Paraná se ofereceram para treinar jovens no aprendizado do uso das flautas sagradas, em troca dos conhecimentos necessários ao funcionamento de suas 
escolas nos mesmos padrões da Escola Tuyuka.

Naturalmente, a implementação destas trocas não é tão simples. Os Makuna contaram-me que a pouca tolerância do sistema educativo colombiano em aceitar um calendário escolar diferenciado para os índios, mais a falta de recursos econômicos, impediam-nos de iniciar seus projetos de escola nos moldes do Tiquié. Por sua vez, os Tuyuka acham perigoso participar do treino com as flautas sagradas, devido ao rigor das dietas e aos perigos do contato com espíritos ancestrais. No Pirá Paraná entendem essa situação e, embora tenham ficado descontentes com a recusa do convite para participar nos rituais de jurupari, asseguram que tal situação poderia causar mal-entendidos, porque, se algum dos participantes do Tiquié adoecesse por não cumprir a dieta, eles poderiam ser acusados de ter feito mal de propósito e, com isso, gerar conflitos que impediriam os interesses comuns. Este exemplo nos mostra como é importante resgatar a confiança mútua, ter cautela com certos processos e não pôr em risco as alianças advindas do reencontro.

Bem, as questões sobre o ciclo anual têm mostrado avanços muito importantes, já que o conhecimento indígena é fundamental para os planos de manejo ambiental e territorial, e aqui se vê uma forte influência da experiência da ACAIPI no contexto de elaboração do seu Plano de Vida, não na metodologia, mas sim em alguns dos resultados finais e na ideia de um eficaz manejo do mundo. Vale a pena lembrar que o Plano de Vida da ACAIPI tomou seu calendário ecológico cultural como o ponto central para reivindicar seu conhecimento e forma de vida, tendo o levantamento sido feito com a participação fundamental dos kumua. NoTiquié, aproveitou-se a metodologia de pesquisa colaborativa com a qual as escolas trabalham para que os Agentes Indígenas de Manejo Ambiental (AIMA's) de cada comunidade, muitos deles formados em várias das Associações-Escolas, se dedicassem durante três anos a elaborar diários, registrando a maior quantidade possível de informações ambientais: aumento ou diminuição das águas do rio, sucessão de constelações, tipos de animais mais avistados em determinado momento, floração e frutificação de frutos silvestres e cultivados, piracemas, etc. Estas informações eram complementadas por narrativas dos mais velhos. Além de elaborar os próprios calendários para o rio, também se publicou um livro, em 2016, como resultado dessa pesquisa (A. Cabalzar, 2016), um apoio fundamental para a governança do território, de acordo com os conhecimentos próprios. Há que se dizer, também, que as publicações produzidas pela Escola Tuyuka influenciaram a ACAIPI, que publicou, em 2015, um belíssimo livro sobre seu sistema de conhecimento, pois, este ganhou o status de patrimônio 
imaterial da humanidade da UNESCO.

No Tiquié, as bases fornecidas pelas Associações-Escolas permitem aos índios avançar em pesquisas em qualquer temática e aumentam o acervo da recuperação de conhecimentos. Uma vez mais, este exemplo comprova que os mecanismos estatais de planejamento, como o Plano de Vida, e instituições como a escola servem para que os índios modifiquem a lógica estatal dominante e a usem para seu próprio benefício, com sua própria marca e estilo. Neste sentido, o fato de terem ficado submetidos a pressões diferentes por parte dos estados nacionais em construção terminou fornecendo aos índios de cada lado da fronteira ferramentas que foram, e são, aproveitadas para benefício próprio e até para a reconstrução das relações sociais que foram interrompidas durante os períodos de maior violência na região fronteiriça.

\section{Considerações finais}

Como pudemos ver ao longo deste texto, o processo de construção dos estados nacionais brasileiro e colombiano atingiu as relações sociais e os conhecimentos dos povos tukano orientais da região de fronteira por meio da imposição de práticas estatizantes, realizadas por diferentes agentes. Os resultados das ações desses agentes estatais foram diferentes em ambos os lados da fronteira e produziram respostas igualmente distintas dos índios, embora estas respostas pareçam seguir a mesma lógica. Os índios, como aqueles mágicos que convertem um lenço de pano num buquê de flores, transformam continuamente elementos da lógica estatal em ferramentas para manter sua forma de vida e de entender o mundo. Isto quer dizer que em meio a situações adversas, eles encontram maneiras de entender, apreender, refletir e se apropriar do que lhes parece conveniente para usá-lo em seu próprio benefício. Sempre "dão a volta por cima” para mostrar que não há nada de sofisticado e útil em se ter uma língua homogênea, uma identidade nacional única, uma suposta história comum tecida pelas elites e que pouco diz para parte da população. Os Makuna e os Tuyuka nos mostram que a multiplicidade e a singularidade podem se construir simultaneamente e por vários caminhos.

O processo de construção da fronteira também nos mostra continuidades sobre os modos de agir dos estados nacionais. A Colômbia, com seu centenário desdém e ausência na região, agora quer transferir funções estatais de controle territorial aos índios, enquanto o Brasil, no fundo, não desistiu da ideia da assimilação e continua mantendo uma presença forte com pelotões do exército, postos de saúde, projetos de desenvolvimento, etc. Enquanto isso, os índios estreitam relações entre suas 
organizações e fazem alianças para garantir a integridade do território comum. Para eles, a linha fronteiriça não existe e transitam pela região com grande facilidade e confor to pois sabem agir e lidar com pessoas e instituições dos dois países. Embora os Estados tentem capturar os índios por meio de várias formas de violência física e/ou simbólica, estes sempre conseguem evadir-se para manter sua autonomia. Por ter tanta inteligência e força, apesar das constantes desgraças vividas nestes últimos séculos de contato com diferentes configurações do estado, os índios sabem resistir e, como a água, fluem pelos caminhos que encontram para reivindicar o direito a ter seu próprio território e forma de vida. Na sua lógica contra o Estado, as fronteiras não são para delimitar, identificar e separar, mas para criar e manter relações, partilhar e conviver.

\section{Agradecimentos}

Agradeço ao Conselho Nacional de Desenvolvimento Científico e Tecnológico (CNPq) pelo financiamento do projeto Povos indígenas, fronteiras e políticas nacionais (Processo 474964/2012-4). Sou muito grato a Luiz Adriano dos Santos pela grandíssima ajuda no Centro de Documentação do Instituto Socioambiental em São Paulo, e ao antropólogo Renato Martelli Soares que me recebeu no mesmo instituto. Agradeço a colaboração de Luana Barcellos, aluna de PIBIC que me ajudou a levantar informações sobre a fronteira no século XIX.

Recebido: 30/05/2018

Aprovado: 12/06/2018

Luis Cayón é Doutor em Antropologia Social pela Universidade de Brasília, professor do Departamento de Antropologia da mesma universidade e, atualmente, Pesquisador Colaborador do Museu de Arqueologia e Etnologia da Universidade de São Paulo. Pesquisa, principalmente, os povos Tukano orientais de fronteira colombo-brasileira sobre cosmologia e xamanismo, manejo ecológico, relações natureza-cultura, noções de pessoa, espaço e tempo, epistemologias e ontologias indígenas, 
parentesco, relações sociais, paisagens, indigenismo, história indígena, formação de sistemas regionais. É autor, dentre outros livros, de En las aguas de yuruparí. Cosmología y chamanismo makuna (2002), Pienso, luego creo. La teoría makuna del mundo (2013). Contato: luiscayon@hotmail.com

\section{Notas}

1. Em 1755, a Coroa Portuguesa elaborou o Diretório dos Índios para definir sua política indigenista depois de ter expulsado os jesuítas. O Diretório queria transformar os índios em vassalos do rei e promovia a construção de aldeamentos. Dentro das vilas, os índios estavam sujeitos ao trabalho compulsório e à tutela dos diretores, cuja função era administrar as aldeias e coordenar os trabalhos. Rapidamente, os diretores controlaram a mão de obra indígena e cometeram inúmeros abusos com os índios.

2. A Casa Arana, mais tarde conhecida como Peruvian Amazon Company, foi uma companhia de exploração de borracha fundada por Julio César Arana, um poderoso cauchero e político peruano. Esta companhia foi responsável pelo genocídio praticado contra vários povos indígenas do interflúvio dos rios Caquetá/Japurá e Putumayo/Iça, na fronteira colombo-peruana, durante os primeiros anos do século XX.

3. Os povos falantes de línguas arawak são os Tariana, Baniwa, Wakuenai, Curripaco, Warekena, Kabiyarí, Yukuna e Matapí ; os de línguas tukano orientais são os Tukano, Wanano, Pirá-tapuyo, Arapaso, Bará, Tuyuka, Pisamira, Desana, Siriano, Tatuyo, Karapana, Barasana, Yiba masã, Makuna, Taiwano, Cubeo, Tanimuka, Letuama, Yuruti, Yauna e Mirití-tapuyo; os de línguas nadahup são os Juhup, Hupda, Döw e Nadëb, assim como os de kákua-nukak são os Kákua e os Nukak, todos estes conhecidos genericamente como Makú; também estão os Carijona ou Karihona, únicos falantes de uma língua karib.

4. Dentre as principais pesquisas publicadas sobre os Tukano orientais se destacam Andrello (2006); Århem (1981, 1998); Århem et. al. (2004); A. Cabalzar (2008); Cabrera (2002); Cayón (2002, 2013); Chernela (1993); Correa (1996); Goldman (1968 [1963], 2004); C. Hugh-Jones (1979); S. Hugh-Jones (1979); Jackson (1983); Koch-Grünberg (1995 [1909]); Lasmar (2005); Oliveira (1995); Reichel-Dolmatoff (1986 [1968], 1978, 1996); Ribeiro (1995); Torres (1969); Trupp (1977).

\section{Referências bibliográficas}

ACAIPI. 2015. HeeYaia Godo Bakari. El Territorio de los Jaguares deYuruparí. Bogotá: Fundación Gaia Amazonas.

ANDERSON, Malcolm. 1996. Frontiers. Territory and State Formation in the ModernWorld. Cambridge: Polity Press.

ANDRELLO, Geraldo. 2006. Cidade do índio. Transformações e cotidiano em Iauaretê. São Paulo: UNESP, ISA; Rio de Janeiro: NUTI.

ÅRHEM, Kaj. 1998. Makuna: Portrait of an Amazonian People. Washington and London: Smithsonian Institution Press.

1981. Makuna social organization. A study in descent, alliance and the formation of corporate groups 
in the Northwestern Amazon. Uppsala: Uppsala Studies in Cultural Anthropology 4. ÅRHEM, Kaj; CAYÓN, Luis; ANGULO, Gladys \& GARCÍA, Maximiliano. 2004. Etnografía Makuna: tradiciones, relatos y saberes de la Gente de Agua. Acta Universitatis Gothenburgensis. No. 17. Bogotá: Universidad de Gotemburgo e Instituto Colombiano de Antropología e Historia (ICANH). BARTH, Fredrik. 2000 [1976]. “Os grupos étnicos e suas fronteiras”. Em: O guru, o iniciador e outras variações antropológicas. F. Barth (org). Rio de Janeiro: Contra Capa Livraria, pp. 25-67.

CABALZAR, Aloísio. 2008. Filhos da cobra de pedra: organização social e trajetórias tuyuka no rio Tiquié (noroeste amazônico). São Paulo: Editora UNESP/ISA; Rio de Janeiro: NuTI.

1999. "O templo profanado: missionários salesianos e a transformação da maloca tuyuka”. In Transformando os deuses. Os múltiplos sentidos da conversão entre os povos indígenas no Brasil. R. Wright (org). Campinas: Editora da Unicamp, pp. 363-398.

CABALZAR, Aloísio (org.). 2016. Ciclos anuais no rio Tiquié. Pesquisas colaborativas e manejo ambiental no Noroeste Amazônico. São Paulo: ISA; São Gabriel da Cachoeira: FOIRN.

CABALZAR, Aloísio; CABALZAR, Flora; VAN DER VELD, Pieter-Jan; TUYUKA, Higinio \& TENÓRIO, Geraldino. 2012. "Escola Indígena Utapinopona Tuyuka". In Educação Escolar Indígena do Rio Negro 1998-2011. Relatos de experiências e lições aprendidas, F. Cabalzar (org). São Paulo: ISA; São Gabriel da Cachoeira: FOIRN.

CABAlZAR, Flora. 2010. Até Manaus, até Bogotá, os Tuyuka Vestem Seus Nomes Como Ornamentos. Geração e transformação de conhecimentos a partir do alto rio Tiquié (Noroeste Amazônico). Tese de Doutorado, Universidade de São Paulo.

CABRERA, Gabriel. 2002. La Iglesia en la frontera: misiones católicas en el Vaupés 1850-1950. Bogotá: Imani, Universidad Nacional de Colombia sede Leticia.

CARDOSO DE OLIVEIRA, Roberto. 1996 [1964]. O índio e o mundo dos brancos. Campinas: Editora da Unicamp.

1976. Identidade, Etnia e Estrutura Social. São Paulo: Pioneira

CARDOSO DE OLIVEIRA, Roberto \& BAINES, Stephen Grant (orgs). 2005. Nacionalidade e etnicidade em fronteiras. Brasília: Editora Universidade de Brasília.

CAYÓN, Luis. 2013. Pienso, luego creo. La teoria makuna del mundo. Bogotá: Instituto Colombiano de Antropología e Historia.

. 2012. "Plans de vie et gestion du monde. Cosmopolitique autochtone du dévelppment en Amazônie colombienne”. Recherches Amérindiennes au Québec, XLII: 63-77.

. 2002. En las aguas de yuruparí. Cosmología y chamanismo Makuna. Bogotá: Ediciones Uniandes.

CHERNELA, Janet. 1993. The Wanano Indians of the Brazilian Amazon: A sense of space. Austin: University of Texas Press.

CLASTRES, Pierre. 2003 [1974]. “A sociedade contra o estado”. In: A sociedade contra o Estado. Pesquisas de antropologia política. São Paulo: Cosac \& Naify. 205-234.

CORREA, François. 1996. Por el camino de la Anaconda Remedio: Dinámica de la organización social entre los Taiwano del Vaupés. Bogotá: Editorial Universidad Nacional-Colciencias.

DIENER, Alexander C. \& HAGEN, Joshua (orgs). 2010. Borderlines and Borderlands. Political Oddities at the Edge of the Nation State. Lanham: Rowman \& Littlefield Publishers. 
DONNAN, Hastings \& WILSON, Thomas M. 1999. Borders. Frontiers of Identity, Nation and State. Oxford \& New York: Berg. (orgs). 2010. Borderland. Ethnographic Approaches to Security, Power, and Identity. Lanham: University Press of America.

EXPOSICIÓN DEL TRATADO DE LÍMITES ENTRE A REPÚBLICA DE LA NUEVA GRANADA Y EL IMPERIO DE BRASIL. 1853. Bogotá: Imprenta del Neo-Granadino.

FAULHAUBER, Priscila. 2001. "A fronteira na Antropologia Social: as diferentes faces de um problema”, BIB, 51: 105-125.

GARCÍA, Clara Inés (org). 2003. Fronteras. Territorios y metáforas. Medellín: Hombre Nuevo Editores, INER.

GOLDMAN, Irving. 2004. Cubeo Hehénewa Religious Thought. Metaphysics of a Northwestern Amazonian People. New York, Chichester, West Sussex: Columbia University Press.

1968 [1963]. Los Cubeo: indios del Noroeste del Amazonas. México: Instituto Indigenista Interamericano.

GÓMEZ, Sebastián. 2014. Frontera selvática. Españoles, portugueses y su disputa por el noroccidente amazónico, siglo XVIII. Bogotá: Instituto Colombiano de Antropología e Historia.

GRIMSON, Alejandro (org). 2000. Fronteras, naciones e identidades. La periferia como centro. Buenos Aires: CICCUS, La Crujía. 9-40.

HUGH-JONES, Cristine. 1979. From the Milk River: Spatial and temporal process in Northwest Amazonia. London: Cambridge University Press.

HUGH-JONES, Stephen. 1979. The palm and the Pleiades: Initiation and cosmology in Northwest Amazonia. London: Cambridge University Press.

JACKSON, Jean E. 1983. The Fish People: Linguistic Exogamy and Tukanoan Identity in Northwest Amazonia. London: Cambridge University Press.

KOCH-GRÜNBERG, Theodor. 1995 [1909]. Dos años entre los indios. 2 Tomos. Bogotá: Universidad Nacional.

LASMAR, Cristiane. (2005). De volta ao Lago de Leite. Gênero e transformação no Alto Rio Negro. São Paulo: UNESP, ISA; Rio de Janeiro: NUTI.

LONDOÑO PAREDES, Julio. 1973. Derecho territorial de Colombia. Bogotá: Imprenta y Litografía de las Fuerzas Militares.

LÓPEZ, Claudia Leonor. 2014. Tikunas brasileiros, colombianos e peruanos: etnicidade e nacionalidade na região das fronteiras do alto Amazonas/Solimões. Belém: Museu Paraense Emílio Goeldi.

2005. "Procesos de formación de fronteras en la región del Alto Amazonas/Solimões: la historia de las relaciones interétnicas de los Ticuna”. In: Nacionalidade e etnicidade em fronteiras. R. Cardoso de Oliveira e S. G. Baines (orgs). Brasília: Editora Universidade de Brasília. 55-83.

MacCREAGH, Gordon. 2001 [1926]. WhiteWaters and Black. Chicago: University of Chicago Press. MARTELLI SOARES, Renato. 2012. Das comunidades à Federação: Associações Indígenas do Rio Negro. Dissertação de Mestrado, Programa de Pós-Graduação em Antropologia Social, Universidade de São Paulo. 
McGOVERN, William. 1927. Jungle Paths and Inca Ruins. New York \& London: The Century Co. MEIRA, Márcio \& POZZOBON, Jorge. 1999. "De Marabitanas ao Apapóris. Um diário de viagem inédito”. Boletim do Museu Paraense Emílio Goeldi, Série Antropologia, 15 (2): 287-335.

MONTEIRO DE NORONHA, José. 2006 [1768]. Roteiro da viagem do Pará até as últimas colonias do sertão da província. São Paulo: Edusp.

NIMUENDAJÚ, Curt. 1982 [1927]. “Reconhecimento dos rios Içana, Aiary e Uapés”. In Textos indigenistas. São Paulo: Edições Loyola.

OLIVEIRA, Ana Gita de. 1995. O mundo transformado. Um estudo da cultura de fronteira no Alto Rio Negro. Belém: Museu Paraense Emílio Goeldi.

PACHECO DE OLIVEIRA, João. 2016. O nascimento do Brasil e outros ensaios. "Pacificação", regime tutelar e formação de alteridades. Rio de Janeiro: ContraCapa.

RAMOS, Alcida Rita. 1998. Indigenism. Ethic Politics in Brazil. Madison: University of Wisconsin Press.

REICHEL-DOLMATOFF, Gerardo. 1996. The forest within. London: Themis Books. .. 1986 [1968]. Desana: simbolismo de los indios Tukano del Vaupés. Bogotá: Procultura. . 1978. El chamán y el jaguar. México: Siglo XXI Editores.

REQUENA, Francisco de. 1992 [1782]. Ilustrados y bárbaros. Diario de la exploración de límites al Amazonas (1782). Madrid: Alianza.

REIS, Arthur. 2006 [1940]. Lobo D’Almada. Um estadista colonial. Manaus: Academia Amazonense de Letras, Prefeitura Municipal de Manaus e Editora Valer.

RIBEIRO, Berta. 1995. Os índios das águas pretas. São Paulo: EDUSP.

RIBEIRO DE SAMPAIO, Francisco Xavier. 1985 [1774-1775]. As viagens do ouvidor Sampaio. Diário da viagem que em visita e correição das povoações da Capitania de S. José do Rio Negro. Manaus: Associação Comercial do Amazonas.

RODRIGUES FERREIRA, Alexandre. 1983 [1787]. Viagem filosófica ao rio Negro. Belém: Museu Paraense Emílio Goeldi.

ROSALDO, Renato. 1989. Culture and Truth:The Remaking of Social Analysis. Boston: Beacon Press.

SAHLINS, Peter. 1989. Boundaries. The Making of France and Spain in the Pyrennes. Berkeley: University of California Press.

SCOTT, James C. 2009. The Art of Not Being Governed. An Anarchist History of Upland Southeast Asia. New Haven \& London: Yale University Press.

TORRES, Alfonso. (1969). Mito y cultura entre los Barasana. Bogotá: Universidad de Los Andes.

TRUPP, Fritz. (1977). Mythen der Makuna. Viena: Elisabeth Stiglmayr.

WILCKENS, Henrique João. 1994 [1781]. “Diário da Viagem ao Japurá”. In: Relatos da Fronteira Amazônica no século XVIII. M. R. Amoroso e N. Farage (orgs). São Paulo: NHII-USP, FAPESP. 19-46.

WILSON, Thomas M. 2000. "Nación, Estado y Europa en la frontera de Irlanda del Norte”. In: Fronteras, naciones e identidades. La periferia como centro. A. Grimson (org). Buenos Aires: CICCUS, La Crujía. 121-138.

WILSON, Thomas M. \& DONNAN, Hastings (orgs). 1998. Border Identities. Nation and State Inter- 
national Frontiers. Cambridge: Cambridge University Press.

WRIGHT, Robin. 2005. História Indígena e do Indigenismo no Alto Río Negro. Campinas: Mercado das Letras; São Paulo: Instituto Socioambiental.

ZÁRATE, Carlos G. 2008. Sílvicolas, siringueros y agentes estatales. El surgimento de una sociedade transfronteriza en la Amazonia de Brasil, Perú y Colombia 1880-1932. Leticia: Universidad Nacional de Colombia; Imani.

Resumo: Este artigo explora os modos como a construção histórica dos estados nacionais na região fronteiriça entre Colômbia e Brasil afetou as relações entre os Tuyuka e os Makuna, povos tukano orientais, localizados no alto rio Tiquié (Brasil) e no rio Pirá Paraná (Colômbia), ao mesmo tempo que analisa as formas e estratégias dos indígenas para lidar com ambos os Estados. Destaca-se a maneira como a lógica indígena entende a fronteira como um espaço não estatal, onde, apesar da coerção dos Estados, é possível tomar elementos das instituições que estes lhes impõem para manter sua lógica contra o Estado e resgatar, num novo contexto, as relações rompidas pelo processo histórico.

Palavras-chave: Fronteira colombo-brasileira; Tukano oriental; espaço não estatal; estado nação
Abstract: This article explores the ways in which the rise of nation-states at the Colombia-Brazil border has affected the relationships between the Tuyuka and Makuna, Eastern Tukanoan peoples who live by the Upper Tiquié River (Brazil) and Pirá Paraná (Colombia), respectively. It also analyzes the indigenous strategies to deal with both states. The central point to the article is the way these Indians understand the international border as a non-state space, where, despite coercion, they can appropriate features of the institutions imposed on them by these states to maintain their anti-state logic and retrieve historically broken relationships in a new context.

Keywords: Colombia-Brazil border; Eastern Tukano; non-state space; nation-state 